\title{
ПРИМЕНЕНИЕ ЛАЗЕРНОЙ ЭМИССИОННОЙ СПЕКТРОМЕТРИИ (LIBS) ДЛЯ IN-SITU ИДЕНТИФИКАЦИИ МАТЕРИАЛОВ СТЕРЖНЕЙ АТОМНЫХ РЕАКТОРОВ
}

\author{
А.Е.Чупров, ООО «Специальные системы.Фотоника», info@sphotonics.ru, Санкт-Петербург, Россия
}

\begin{abstract}
Метод лазерной эмиссионной спектроскопии (Laser-Induced Breakdown Spectroscopy - LIBS) позволяет определить элементный состав исследуемого материала. Однако при поиске стальных компонентов атомных реакторов, предрасположенных к повышенному риску коррозии из-за аномально низкой концентрации кремния, идентификация затруднена. Характерные эмиссионные линии кремния, которые находятся преимущественно в УФ-области спектра, сильно поглощаются в оптическом волокне, используемом в инструментальной реализации метода. Представлен элегантный способ, как обойти эти ограничения при решении вопроса своевременного вывода из эксплуатации стержней из бракованного материала.
\end{abstract}

Статья поступила в редакцию 13.02.2019

Статья принята к публикации 15.04.2019

\section{ИСТОРИЯ ВОПРОСА}

В августе 1993 года на двух английских атомных электростанциях, эксплуатирующих реакторы типа "Магнокс", на вторичных управляющих стержнях были обнаружены дефекты трещиноподобного типа [1]. Стало известно, что в партии используемых в конструкции реактора управляющих стержней присутствуют компоненты, наружные оболочки которых, как оказалось, были изготовлены из стали с аномально низкой концентрацией кремния, и, таким образом, они подвергались повышенному риску коррозии и возможному преждевременному выходу из строя [2]. Местоположение этой партии управляющих стержней в обоих реакторах, к сожалению, оставалось неизвестным. Такие обстоятельства привели к решению использовать метод лазерной эмиссионной спектроскопии LIBS (Laser-Induced Breakdown Spectroscopy), для чего следовало провести модификацию метода для использования его в условиях in-situ.

Рассматриваемые управляющие стержни находились в эксплуатации и, следовательно, были очень радиоактивными. Физический отбор проб с последующим лабораторным анализом, помимо того, что представлял собой длительный и дорогостоящий процесс, был исключен из-за риска нарушения механической целостности управляющих стержней. Возможности LIBS-метода для дистанционного и практически не разрушающего анализа могли обеспечить бюджетное решение этой проблемы. Поэтому была принята программа ускоренной разработки и создания волоконнооптического зондового LIBS-прибора, способного идентифицировать подозрительные компоненты.

\section{LIBS-PЕШЕНИЕ}

На первых этапах разработки программы было очевидно, что измерение низких уровней кремния с помощью LIBS-метода по традиционной схеме измерений затруднительно. Причина в том, что характерные эмиссионные линии кремния находятся преимущественно в УФ-области спектра и потому будут сильно поглощаться оптическим волокном. Это может поставить под угрозу работу LIBS-прибора, и необходимый уровень точности измерения концентрации кремния вряд ли будет достигнут. Однако спецификация стали для корпуса управляющего стержня показала, что партия с низким содержанием кремния может быть однозначно идентифицирована, если с достаточной точностью измерить уровни концентрации марганца и меди. Для этих целей был разработан и откалиброван LIBS-прибор для измерения содержания марганца и меди в стали. Общая конструкция LIBS-прибора, разработанного для этой цели, схематически показана на рисунке [3].

Подозрительные управляющие стержни были извлечены из реактора и опущены в установку

Компания "Специальные Системы. Фотоника" является эксклюзивным дистрибьютором компании LUMIBIRD (Франция) и оказывает техническую поддержку для всей линейной продукции LUMIBIRD на территории России и Таможенного Союза. Вы можете получить любую дополнительную информацию о продукции и технологиях LUMIBIRD, обратившись к специалистам нашей компании. 
с горячей камерой, оборудованную устройствами дистанционного управления. Дистанционная головка LIBS-прибора была спроектирована так, чтобы проходить через отверстие доступа диаметром 180 мм в горячую камеру и крепиться к исследуемому управляющему стержню с помощью копирующего манипулятора (КМ). Головка дистанционного управления была подключена к главному блоку управления LIBS-прибора с помощью шлангокабеля длиной 10 м, обеспечивающего механическую защиту оптических волокон и электрических кабелей. В конструкцию прибора был встроен маломощный $\mathrm{He}-\mathrm{Ne}$-лазер, выход которого был запущен в то же оптическое волокно, которое использовалось для передачи излучения мощного Nd:YAG-лазера на измерительный участок. По отраженному излучению Не-Ne-лазера регистрировался момент времени, когда поверхностный оксидный слой исчезал из-за лазерной абляции. Таким образом контролировался момент, когда лазерному воздействию, необходимому для проведения LIBS-измерения, подвергался слой стали, лежащий под слоем окисла. На практике для подготовки поверхности стали использовалось несколько сотен лазерных импульсов, а затем еще сто лазерных импульсов для LIBS-анализа. Разработка LIBS-прибора оказалась очень успешной,
The LIBSProbe design successfully uses compact nanosecond Nd: YAC lasers from the Quantellby LUMIBIRD series. These are the ULTRA and CFR models in an airtight, dustproof, waterproof case with a power supply and cooling system in one portable, lightweight device - ICE450. All laser systems that belong to the BSL series are tested for vibration resistance and heat resistance that meet the highest military standards for operation in the most unpretentious conditions (MIL-STD-810F).

Special Systems. Photonics LLC is the exclusive distributor of the company LUMIBIRD (France) and provides technical support for the entire LUMIBIRD product line in Russia and the Customs Union. You can get any additional information about LUMIBIRD products and technologies by contacting our specialists.

и каждый из управляющих стержней, подозреваемых в предрасположенности к повышенному риску коррозии и возможному преждевременному выходу из строя, был легко идентифицирован.

\section{СПИСОК ЛИТЕРАТУРЫ}

1. URL [www.appliedphotonics. co.uk].

2. Шульга А. В. Влияние водорода на упрочнение быстрозакаленной ферритномартенситной стали.2018; 9(1): 28-36.

3. Duckworth A. Remote metal analysis by laser-induced breakdown spectroscopy. British Nuclear Engineering Society (BNES) Conference Proceedings. Remote Techniques for Hazardous Environments. 1995; 259-263.

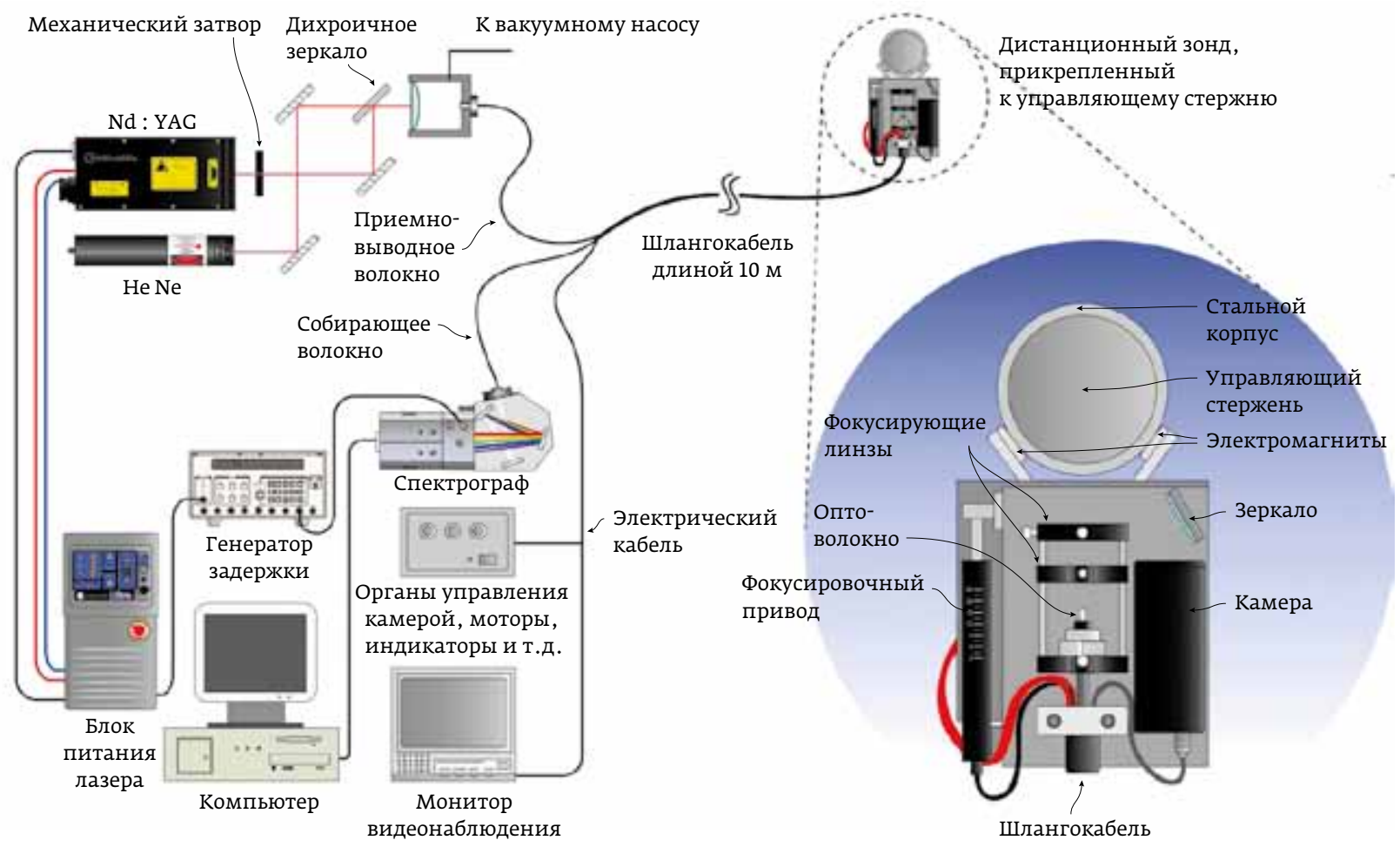

Схема прибора ЛОЭС, разработанного для измерения содержания марганца и меди в стальных оболочках управляющих стержней реакторов типа "Магнокс". 